\title{
Alcohol and cardiovascular mortality in Moscow; new evidence of a causal association
}

\author{
Laurent Chenet, Martin McKee, David Leon,Vladimir Shkolnikov, Sergei Vassin
}

\begin{abstract}
Background-In explaining recent trends in Russian mortality, alcohol drinking has often been put forward as a major factor. However, cardiovascular disease remains the major cause of death in Russia and alcohol is currently viewed as having a protective effect on heart disease. This study explores this apparent paradox by examining daily trends in deaths from cardiovascular disease in Moscow.

Subjects-Those dying in Moscow in the years 1993-1995.

Methods-Analysis of daily variation in deaths based on data from Moscow City death certificates.

Results-There is a significant increase in deaths from alcohol poisoning, accidents, and violence and cardiovascular diseases on Saturdays, Sundays, and Mondays. This is especially marked for sudden deaths. This pattern is consistent with the known pattern of drinking in Russia, which is more likely to take place in binges than is the case in other countries.

Conclusion-A possible causative role for alcohol in sudden cardiovascular death is suggested as there are no other obvious explanations for this pattern, which cannot be accounted for by daily variations in traditional risk factors such as smoking or lipids. Although this is inconsistent with the prevailing view in the West that alcohol is seen as cardioprotective, there is considerable supporting evidence from a necropsy study and from studies in other places with a similar pattern of drinking. In countries such as Russia, where patterns of drinking differ considerably from that in the West, binge drinking can be an important cause of sudden cardiac death. This has important implications for estimates of the amount of mortality worldwide attributable to specific risk factors and thus for national and international policy.

(F Epidemiol Community Health 1998;52:772-774)
\end{abstract}

Chenet

$\mathrm{M} \mathrm{McKee}$

D Leon

Centre of Demography and Human Ecology,

Institute for Economic

Forecasting, Moscow,

Russian Federation

V Shkolnikov

$S$ Vassin

Correspondence to:

Dr L Chenet.

Accepted for publication 9 March 1998.

The Russian mortality crisis in the 1990s has attracted much interest but is still poorly understood. Since the mid-1980s, Russian life expectancy at birth displayed unprecedented fluctuations: first rising rapidly during Gorbachev anti-alcohol campaign, then decreasing by 6.5 years for men and 3.5 years for women. Young adults (35-49) have been most severely hit by this mortality crisis. Deaths from accidents and violence as well as alcohol related deaths seem to play a major part, ${ }^{1}$ with death rates from accidents and violence increasing fivefold for men in their 40s between 1987 and 1994, and alcohol related mortality increasing sevenfold. ${ }^{2}$ These increases, as well as the substantial but short lived decline in mortality coinciding with the anti-alcohol campaign of the mid-1980s, point to alcohol consumption as a major factor in the present mortality crisis. ${ }^{3}{ }^{4}$

However, the main cause of death contributing to these overall mortality trends is cardiovascular diseases. The most frequent single cause of death is "coronary atherosclerosis" (code 093 in the Soviet classification of diseases). Deaths from this cause have contributed substantially to the recent fluctuation in mortality, exhibiting a sharp fall in the years after 1985, coinciding with Gorbachev's antialcohol campaign, followed by an even greater increase. These changes were strikingly similar to the observed changes in deaths from accidents, violence, and alcohol related causes. ${ }^{4}$

To suggest that alcohol is a major risk factor for cardiovascular disease in Russia, is at odds with the prevailing view that alcohol protects against circulatory diseases. However, we hypothesised that an appreciable proportion of what is described as "coronary atherosclerosis" in Russia is a result of a disease process that differs fundamentally from what is understood by the term in the West. The sharp temporal variations of the death rates and the demographic characteristic of those most at risk (typically aged 35-49) point to an acute impact of alcohol on the cardiovascular system that does not entirely fit the description of "coronary atherosclerosis", but suggests more sudden cardiac death. To test our hypothesis we looked at daily variations in number of deaths in Moscow.

Alcohol consumption in Russia is characterised by binge drinking, leading to an increase in deaths from accidents, violence, and alcohol poisoning at weekends. If alcohol is a risk factor for cardiovascular deaths in Russia, such deaths might be expected to show any daily variation seen for more unambiguously alcohol related deaths.

\section{Methods}

We have analysed deaths from various causes in Moscow among those aged 35 to 74 (238 225 deaths) by day of week, using data extracted by Mosgorstat, the Moscow Statistical Committee, from all death certificates for the city for 1993 to 1995 . The data include variables such as dates of birth and death, age, sex, cause of death according to the Soviet classification of diseases (which contains 175 categories based 
Table 1 Daily variation in deaths of Moscow residents, 1993-95

\begin{tabular}{|c|c|c|c|c|c|c|c|c|c|c|}
\hline & \multicolumn{10}{|c|}{ Men (35-74) } \\
\hline & \multicolumn{2}{|c|}{ Cardiovascular } & \multicolumn{2}{|c|}{ Cancer } & \multicolumn{2}{|c|}{ Alcohol } & \multicolumn{2}{|c|}{$\begin{array}{l}\text { Accident and } \\
\text { violence }\end{array}$} & \multicolumn{2}{|l|}{ Other } \\
\hline & No & $(\%)$ & No & $(\%)$ & No & $(\%)$ & No & $(\%)$ & No & $(\%)$ \\
\hline Sunday & 10042 & 14.4 & 3824 & 14.2 & 150 & 16.5 & 3569 & 14.4 & 3459 & 13.6 \\
\hline Monday & 10184 & 14.6 & 3792 & 14.1 & 123 & 13.6 & 3409 & 13.8 & 3731 & 14.7 \\
\hline Tuesday & 9719 & 13.9 & 3868 & 14.4 & 128 & 14.1 & 3399 & 13.7 & 3680 & 14.5 \\
\hline Wednesday & 9817 & 14.0 & 3866 & 14.4 & 119 & 13.1 & 3465 & 14.0 & 3586 & 14.1 \\
\hline Thursday & 9833 & 14.1 & 3907 & 14.5 & 128 & 14.1 & 3490 & 14.1 & 3683 & 14.5 \\
\hline Friday & 10030 & 14.3 & 3862 & 14.4 & 104 & 11.5 & 3720 & 15.0 & 3671 & 14.4 \\
\hline Saturday & 10309 & 14.7 & 3735 & 13.9 & 155 & 17.1 & 3702 & 15.0 & 3612 & 14.2 \\
\hline $\mathrm{p}$ value for $\chi^{2} 6 \mathrm{df}$ & \multicolumn{2}{|c|}{$\begin{array}{l}0.0001 \\
\text { Women }(35-74)\end{array}$} & \multicolumn{2}{|c|}{0.5193} & \multicolumn{2}{|c|}{0.0246} & \multicolumn{2}{|c|}{$<0.0001$} & 0.0371 & \\
\hline Sunday & 6820 & 14.4 & 3281 & 14.4 & 30 & 18.2 & 1040 & 14.8 & 1823 & 14.0 \\
\hline Monday & 6700 & 14.1 & 3320 & 14.6 & 25 & 15.2 & 989 & 14.1 & 1802 & 13.8 \\
\hline Tuesday & 6673 & 14.1 & 3170 & 13.9 & 19 & 11.5 & 1002 & 14.3 & 1820 & 14.0 \\
\hline Wednesday & 6692 & 14.1 & 3276 & 14.4 & 31 & 18.8 & 1002 & 14.3 & 1860 & 14.3 \\
\hline Thursday & 6767 & 14.3 & 3162 & 13.9 & 19 & 11.5 & 972 & 13.9 & 1892 & 14.5 \\
\hline Friday & 6880 & 14.5 & 3333 & 14.6 & 15 & 9.1 & 1045 & 14.9 & 1975 & 15.1 \\
\hline Saturday & 6820 & 14.4 & 3254 & 14.4 & 26 & 15.8 & 954 & 13.6 & 1865 & 14.3 \\
\hline $\mathrm{p}$ value for $\chi^{2} 6 \mathrm{df}$ & 0.4798 & & 0.211 & & 0.15 & & 0.354 & & 0.0871 & \\
\hline
\end{tabular}

Table 2 Distribution (\%) of male deaths from "coronary atherosclerosis" and "other cardiac diseases", Moscow 1993-95

\begin{tabular}{ll}
\hline Day & $\%$ Of total deaths \\
\hline Sunday & 14.8 \\
Monday & 14.4 \\
Tuesday & 13.8 \\
Wednesday & 13.8 \\
Thursday & 14 \\
Friday & 14.4 \\
Saturday & 14.8 \\
\hline
\end{tabular}

on ICD-9), and a variety of socioeconomic variables. Earlier work has shown that the quality of Russian data is comparable to that in the west. ${ }^{2}$ These were supplied in an ASCII file and analysis was undertaken using SPSS.

\section{Results}

As expected, deaths in Moscow from alcohol poisoning and for accidents and violence, (both closely linked to alcohol consumption) follow a weekly pattern with a higher number of deaths during the weekend (table 1). Moreover, there are more deaths from cardiovascular diseases on Saturdays, Sundays, Mondays, than on Tuesday, Wednesdays, Thursdays or Fridays. This is statistically significant for men. For women although not significant, a higher proportion of deaths from cardiovascular diseases is observed at the weekend. For neoplasms, for which there is no suggestion of an acute effect of alcohol, there is no evidence of a weekly pattern.

Disaggregating the cardiovascular death to give finer categories shows that two causes of deaths are responsible for this weekly pattern of death: 093 or "coronary atherosclerosis" and 097 "other cardiac diseases" (table 2).

Table 3 Percentage difference from what would be expected if no daily variation in deaths from "coronary atherosclerosis" and "other cardiac diseases" by age group, Moscow 1993-95

\begin{tabular}{lrrrrrrr}
\hline & $35-39$ & $40-44$ & $45-49$ & $50-54$ & $55-59$ & $60-64$ & $65-69$ \\
\hline Sunday & -7.6 & 9.9 & 2.9 & 2.2 & 3.6 & 3.6 & 2.2 \\
Monday & 8.5 & 1.5 & -4.1 & -2.0 & -2.7 & 5.0 & 0.8 \\
Tuesday & -9.7 & -2.0 & -2.0 & -3.4 & -2.0 & -4.1 & -2.0 \\
Wednesday & -6.2 & -6.9 & -5.5 & -6.2 & -4.1 & -5.5 & -0.6 \\
Thursday & -5.5 & -10.4 & 2.9 & 4.3 & -2.7 & -2.0 & -2.0 \\
Friday & 5.0 & 4.3 & -2.0 & 5.0 & 2.9 & -0.6 & -0.6 \\
Saturday & 14.8 & 4.3 & 8.5 & 0.1 & 5.0 & 3.6 & 1.5 \\
\hline
\end{tabular}

When deaths from "coronary atherosclerosis" and "other cardiac diseases" are examined by age group, the weekend effect is most obvious in those aged under 50. For clarity, the results in table 3 show the percentage difference from what would be expected if there was no daily variation. Thus, among those aged 35 to 39 , there are almost $10 \%$ fewer deaths than would be expected on Tuesdays and almost $15 \%$ more deaths than expected on Saturdays.

An alternative explanation for the day of week effect is that the shortage of hospital staff during the weekend could explain the higher mortality. However, there is no weekly variability for cancer. Moreover, only $38 \%$ of all deaths occurred in hospital, and only $37 \%$ of cardiovascular deaths. If the same analysis is performed separately according to place of death, the day of the week effect is strengthened for cardiovascular deaths outside of hospital, which is consistent with the idea of a sudden cardiac death, but is absent for deaths in hospital.

\section{Discussion}

This research is subject to certain caveats: we have not been able to conduct validation studies such as comparison of death certificates with hospital case notes. Nor did we have access to necropsy reports. Finally, the Soviet classification used comprises only 175 causes of death so does not allow for precise diagnostic categories such as provided by ICD 9 and it emphasises immediate causes of death at the expense of underlying ones. ${ }^{5}$ However, a detailed examination of the data has been undertaken and no important discontinuities or other evidence of poor quality data has been identified. In addition, we have not been able to link individual data on alcohol consumption with patterns of deaths so, as with all ecological studies, the results should be treated with caution until further evidence is available.

Although in contrast with widely held views, the suggestion that a significant proportion of sudden deaths in Moscow might be caused by alcohol is not new. A report published in 1986 identified alcohol as the most likely cause in $17 \%$ of those dying suddenly although this 
figure was higher among those under $50(35 \%){ }^{7}$ It also found, at necropsy, that most cases had no significant coronary disease but, when material could be collected soon after death, most had evidence of cardiomyopathy, with analysis of mitochondrial enzyme levels indicating that this was caused by alcohol rather than other causes.

In the West, the prevailing view is that alcohol consumption reduces the risk of heart disease, exemplified by the statement in the World Bank/WHO report on the global burden of disease that "after correcting for smoking, alcohol consumption exerts a protective effect on cardiovascular death at all levels of consumption". ${ }^{8}$ However, this is based largely on research conducted in countries where alcohol consumption is lower than in Russia and, specifically, where those who drink very heavily are likely to exist on the margins of society and to be excluded from studies based on occupational cohorts. Furthermore, studies that have focused specifically on sudden deaths have found a positive association with alcohol. ${ }^{9-11}$ Of particular note, a retrospective study of 100 sudden deaths in Newcastle upon Tyne, England, compared with 100 non-fatal myocardial infarctions, showed that a higher proportion of men who died had taken alcohol three hours before deaths and that sudden deaths were most common on Saturdays whereas this was not the case for non-fatal myocardial infarction. ${ }^{12}$ There is also supporting evidence from several studies undertaken in Finland, where the pattern of drinking has traditionally resembled that seen in Russia. In one Finnish study, the authors argue that "in cases of sudden death, the aetiological role of coronary heart diseases might have been overestimated among alcohol consumers, because there is evidence that alcohol in itself can injure the myocardium and cause a dangerous arrhythmia or myocardial infarction". 8 A recent Finnish study has reported a relative risk of 6.5 of fatal myocardial infarction in those drinking six or more bottles of beer in a session compared with those drinking less than three ${ }^{13}$ and another found and an over twofold increase in the risk of cardiac death in those suffering frequent hangovers. ${ }^{14}$

The finding that more people in Moscow die of cardiovascular diseases during the weekend cannot plausibly be accounted for by weekly variations in traditional risk factors such as lipids and tobacco consumption. However, our results are entirely consistent with the idea that high alcohol consumption is a major determinant of the Russian mortality crisis. The observation that there are more deaths from cardio- vascular diseases on Monday than on Friday is consistent with a latency period between alcohol use and cardiovascular effects (typically between 12-24 hours) which has been described, for example, for blood pressure. ${ }^{15}$ Moreover, the distribution shown is likely to substantially underestimate the impact of alcohol related cardiovascular mortality as it is implausible that all heavy alcohol consumption occurs at weekends. ${ }^{16}$

Although the negative impact of binge drinking on cardiovascular mortality has been described at the individual level, this is to our knowledge the first time that it has been illustrated at the population level. This has obviously very important consequences, not only for Russian policy makers but also for the wider international community as it brings into question the estimates of the global burden of disease attributable to alcohol. ${ }^{8}$

The authors also wish to acknowledge the invaluable contribution of Professor Richard Peto.

Funding: this research was funded through a grant from the Department for International Development's Know How Fund. However, DFID can not accept any responsibility for any information provided or views expressed.

1 Meslé F, Shkolnikov V, Vallin J. Brusque montée des morts violentes en Russie. Population 1994;3:773-800.

2 Meslé $\mathrm{F}$, Shkolnikov V, Hertrich V, et al. Tendances récentes Mesle $\mathrm{F}$, Shkolnikov V, Hertrich V, et al. Tendances récentes
de la mortalité par causes en Russie, 1965-93 - volume 2: de la mortalité par causes en Russie, 1965-93 - volume 2; Annexes. Dossiers et Recherches 50.

3 Ryan M. Alcoholism and rising mortality in the Russian Federation. BMF 1995;310:646-8.

4 Leon D, Chenet L, Shkolnikov VM, et al. Huge variation in Russian mortality rates 1984-1994: artefact, alcohol, or what? Lancet 1997;350:383-8.

5 Moiseev V, Ogurtsov P. Klinitcheskiye maski alkogolnoi blezni [Clinical masks of alcohol related disease]. Meditsinskaya Gazeta 17 Mar 1996, 21.

6 Ogurtsov P. Kontseptsiya alkogolnoi bolezni [Conception of alcohol related disease]. Meditsinskaya Gazeta 16 Feb 1996, 14

7 Vikhert AM, Tsiplenkova VG, Cherpachenko NM. Alcoholic cardiomyopathy and sudden cardiac death. $\mathcal{F} \mathrm{Am}$ Coll Cardiol 1986;8 (suppl A):3-11A.

8 Murray CIL, Lopez AD, eds. The global burden of disease. Boston MA: WHO, Harvard School of Public Health, Boston MA: WHO, Har
World Bank, 1996:307-8.

9 Suhonen O, Aromaa A, Reunanen A, et al. Alcohol consumption and sudden coronary death in middle aged consumption and sudden coronary death in middle aged Finnish Men. Acta Medica Scandinavica 1987;221:335-41.
Gordon T, Kannel WB. Drinking habits and caridovascular Gordon T, Kannel WB. Drinking habits and caridovascular
disease: the Framingham Study Am Heart f 1983;105:66773.

11 Wannamethee G, Shaper AG. Alcohol and sudden cardiac death. Br Heart f 1992;68:443-8.

12 Myers A, Dewar HA. Circunstances attending 100 sudden deaths from coronary artery disease with coroner's necropsies. Br Heart F 1975;37:1133-43.

13 Kauhanen J, Kaplan GA, Goldberg DE, et al. Beer drinking and mortality: results from the Kuopio ischaemic heart disease risk factor study, a prospective population based study. BMF 1997;315:846-51.

14 Kauhanen J, Kaplan GA, Goldberg DD, et al. Frequent hangovers and cardiovascular mortality in middle-aged men. Epidemiology 1997;8:310-14.

15 Wannamethee G, Shaper AG. Patterns of alcohol intake and risk of stroke in middle-aged British men. Stroke 1996;27: risk of strok $1033-9$.

16 White S. Russia goes dry. Cambridge: Cambridge University Press, 1996. 